Short communication

\title{
Removal of azo dye in an up-flow membrane-less bioelectrochemical system integrated with bio-contact oxidation reactor
}

\author{
Yuan Pan ${ }^{\mathrm{a}, 1}$, Youzhao Wang ${ }^{\mathrm{a}, 1}$, Aijuan Zhou ${ }^{\mathrm{b}}$, Aijie Wang ${ }^{\mathrm{c}}$, Zongting Wu ${ }^{\mathrm{a}}$, Liting $\mathrm{Lv}^{\mathrm{a}}$, Xianjin $\mathrm{Li}^{\mathrm{a}}$, \\ Kuo Zhang ${ }^{\text {a }}$, Tong Zhu ${ }^{\text {a,* }}$ \\ a School of Mechanical Engineering and Automation, Northeastern University, 3-11, Wenhua Road, Heping District, Shenyang 110004, China \\ ${ }^{\mathrm{b}}$ College of Environmental Science and Engineering, Taiyuan University of Technology, Taiyuan 030024, China \\ ${ }^{\mathrm{c}}$ Key Laboratory of Environmental Biotechnology, Research Center for Eco-Environmental Sciences, Chinese Academy of Sciences, Beijing 100085, China
}

\section{H I G H L I G H T S}

- BES-BCO has the capability for efficient COD reduction, and AO7 decolorization.

- The decolorized products of azo dyes were further degraded in BES-BCO.

- The bioanode activity was inhibited at high DO concentration.

- The oxygen and AO7 competed as electron acceptor at BES unit.

\section{A R T I C L E I N F O}

\section{Article history:}

Received 6 March 2017

Received in revised form 22 May 2017

Accepted 24 May 2017

Available online 27 May 2017

\section{Keywords}

Bioelectrochemical systems

Bio-contact oxidation

Azo dye removal

\begin{abstract}
A B S T R A C T
An up-flow membrane-less bioelectrochemical system integrated with bio-contact oxidation (BES-BCO) was developed for degradation and/or mineralization of the Acid Orange 7 (AO7) in wastewater. The performance of BES-BCO was evaluated based on decolorization removal efficiency, chemical oxygen demand (COD) removal efficiency and the concentration of decolorized byproducts in effluent. The study found that the BES-BCO system can degrade AO7 and COD effectively. Further, the toxic decolorized byproducts of azo dye, which are not generally degrade in the traditional BES system, can be further mineralized by the BES-BCO system. In addition, the COD removal efficiency increased with the increase of aeration at BCO. However, higher DO concentration at anode can hinder the electrons transfer between anode and exoelectrogen, resulting in a significant decrease of decolorization removal efficiency. This study provided a novel compact technology for advanced treatment of azo dyes wastewater for engineering applications, and concluded that the integrated BES-BCO system is effective for advanced treatment of azo dye-containing wastewater.
\end{abstract}

(C) 2017 Published by Elsevier B.V.

\section{Introduction}

The dye-containing wastewater with high organic concentration and high chroma can cause severe environmental pollution and can have adverse impacts on human health if discharged without any treatment. Therefore, it is important to treat the dyecontaining wastewater below threshold limits before the discharge [1]. Azo dye, characterized by one or more azo bonds $(-\mathrm{N}=\mathrm{N}-)$, is the most common organic dye that has been widely used in industries such as the textile, leather, and plastics industries. Azo dyes

\footnotetext{
* Corresponding author.

E-mail address: tongzhu@mail.neu.edu.cn (T. Zhu).

1 These authors contributed equally to this work and should be considered co-first authors.
}

are difficult to be mineralized because of its complex structure and high molecular weight.

Several physical-chemical technologies such as flocculation, adsorption, and advanced oxidation have been proposed to remove azo dye from dye-containing wastewater. However, these methods have significant drawbacks including high capital cost, high operating cost and production of a large quantity of sludge. In comparison, biological treatment is proposed as an alternative approach to remove azo dyes since they are effective and economical. Anaerobic treatment processes can remove chromaticity color effectively, though it has a slower decoloration rate [2]. Moreover, the decolorized products of azo dyes are toxic and do not effectively degrade further in anaerobic conditions. Hence, the aerobic treatment is required to mineralize the decolorized products of azo dyes after anaerobic treatment process [3]. However, anaerobic-aerobic 
biological process has their disadvantages such as the need for a large area, low removal rate and low removal efficiency, which restrict the utilization of biological treatment methods.

Different bioelectrochemical systems (BESs) have been proposed for the treatment of azo dyes and high-concentration organic wastewater [4-6]. In BESs, azo bonds are broken at the cathode by reduction, while organics undergo microbial oxidation at anode, which simultaneously provides electrons for reduction at cathode. Compared with conventional electrochemical and anaerobic biological processes, the energy consumption and electron donor requirements are significantly lower in BESs [7]. However, conventional BESs have disadvantages similar to the anaerobic biological processes including the incomplete degradation of toxic byproducts $[8,9]$. In previous studies, a membrane-free up-flow biocatalyzed electrolysis reactor (UBER) and aerobic bio-contact oxidation reactor (ABOR) in series were used to treat azo dye. The system achieved a decolorization efficiency of $94.8 \pm 1.5 \%$ and decolorized products were further mineralized [7]. However, two series technology was complex and required significantly large areas.

Due to the rapid urbanization, energy and spatial constrains have received significant attention in recent years [10]. The compact technology can effectively utilize energy and space in addition to reducing the amount of air needed, reducing the pumping requirements such as recirculation pumping, and minimizing the foot-print. Integrated bioreactors based on compact technology have advantages of smaller capital investments, and small occupation of land, and are applied widely in the treatment of different wastewaters. In addition, trace dissolved oxygen is delivered to anode area due to the integrated aerobic BCO unit. Some studies reported that trace oxygen stimulated bacterial growth, enhanced the current generation capability in MFCs, and enabled anaerobic microbial process that utilizes recalcitrant organics [11].

In this study, an up-flow membrane-less BES integrated with bio-contact oxidation based on the compact technology was developed to effectively degrade or mineralize the Acid Orange 7 (AO7) in wastewater. The AO7 and chemical oxygen demand (COD) removal efficiencies at different initial $\mathrm{AO} 7$ concentration were also studied. The decolorized products were analyzed to determine the degree of biodegradation. The influence of different dissolved oxygen concentration on the removal of AO7 and COD were also investigated. This study provides a potential technology to achieve the azo dye degradation in real-world engineering applications.

\section{Materials and methods}

\subsection{Configuration of BES-BCO reactor and operation}

The laboratory scale integrated BES-BCO bioreactor, which was made of polymethyl methacrylate, comprised two units, namely a BES unit in the lower part and a BCO unit in the upper part. The reactor was a cylinder (diameter $12 \mathrm{~cm}$ and height $54 \mathrm{~cm}$ ) with a total empty volume (TV) of $5.95 \mathrm{~L}$ and an effective liquid volume of $4 \mathrm{~L}$ excluding the bio-electrodes (bio-cathodes and bio-anode) and biofilm carriers.

The bio-electrode in reactor contained ring-shaped carbon brushes of $2.5 \mathrm{~cm}$ length, and a ring radius of $7.5 \mathrm{~cm}$ (Toray Industries, Inc. Japan) and welded through 3 piece of titanium wire with the reactor. The electrodes were punctured through the rubber stopper used for sealing. The bio-cathodes and the bio-anodes, both with 2 carbon brushes, were fixed on the lower portion and upper portion of BES, respectively. The net cathodic compartment (NCC) and net anodic compartment (NAC) were $1.5 \mathrm{~L}$. The bioelectrodes were connected to external wires and a power supply using titanium wire ( $1 \mathrm{~mm}$ diameter, Jingzhou city haote materials
Co., Ltd.) as current collector. Biofilm carriers made up of porous plastic fiber were used for supporting microbial growth in the aerobic reactor. Biofilm carriers were tied to a ring-shaped frame (ID $3.5 \mathrm{~cm} \times 20 \mathrm{~cm}$ height) installed in the upper BCO unit. The net BCO compartment (NBC) was $0.8 \mathrm{~L}$.

Two saturated calomel reference electrodes (SCE) were installed between the anode and the cathode to measure the potential. The DC power supply between the anode and cathode was $700 \pm 10 \mathrm{mV}$. The bio-electrodes and the reference electrodes were connected to a data acquisition system. An external resistor (Rex) of $10 \Omega$ was connected in the circuit. The voltage across Rex and the cathode potential were recorded every 15 min using the data acquisition system.

Aerator was placed at the bottom of the ring-shaped frame in BCO unit to supply the oxygen for the growth of microbes on bio-carriers. A DO probe was installed at $\mathrm{BCO}$ unit to monitor the concentration of DO in real time. There were 3 sampling points along the BES-BCO reactor at the cathode, the anode, and the biocontact-oxidation. The BES-BCO reactor was operated in a continuous mode with a peristaltic pump (BT100-2J, Longer Precision Pump). The schematic diagram of BES-BCO reactor is given in Fig. 1.

\subsection{Inoculum and substrates}

The inoculation sludge for BES was mixed sludge in lakebeds (NanHu park, ShenYang), while the anaerobic sludge was collected from the anaerobic tank of a wastewater treatment plant. Biofilm carriers of BCO was inoculated with aerobic sludge collected from the wastewater treatment plant. The composition of synthetic azodye wastewater containing carbon sources, buffer solutions, and nutrients was as follows [5]: glucose (as carbon sources) $(1 \mathrm{~g} / \mathrm{L})$, Acid orange 7 (AO7) $(25,50,75,100 \mathrm{mg} / \mathrm{L}), 50 \mathrm{mM}$ phosphate buffer solution (PBS, pH: 7.0), $\mathrm{NH} 4 \mathrm{Cl}(0.41 \mathrm{~g} / \mathrm{L}), \mathrm{KCl}(0.14 \mathrm{~g} / \mathrm{L})$, trace element solution $(1 \mathrm{ml})[12,13]$, and vitamin solution $[13,12]$. The reaction solution was purged with nitrogen gas for $15 \mathrm{~min}$ to remove possible dissolved oxygen in the solution.

\subsection{Chemicals and analytical methods}

The concentration of AO7 was determined using UV-Vis spectrometer (DR6000, Hach co., Ltd). Chemical oxygen demand (COD) was measured using the APHA Standard Methods [14]. The decolorized products of the AO7, and sulfanilic acid were quantified using the chromatographic analysis. Chromatographic analysis was performed on a Shimadzu 30A UFLC System (Shimadzu Corporation, Japan) that consisted of a binary pump, an on-line degasser, an auto-sampler, a column temperature controller and a UV/Vis detector coupled with the Lab solution software. Separation was achieved with an Agilent ZORBAX SB-C18 (4.6 mm $\times 150 \mathrm{~mm}$, $5 \mu \mathrm{m}$ ) column with a sample injection volume of $10 \mu \mathrm{L}$. The mobile phase was composed of $10 \mathrm{mmol} / \mathrm{L}$ dibasic sodium phosphate solution adjusted with phosphoric acid to a $\mathrm{pH}$ of 7.0 (A) and methanol (B), with a gradient elution as follows: $0.01 \mathrm{~min}, 90 \%(\mathrm{~A}) ; 3 \mathrm{~min}$, 90\% (A); $3.1 \mathrm{~min}, 10 \%(\mathrm{~A})$; $6 \mathrm{~min}, 10 \%(\mathrm{~A}) ; 6.1 \mathrm{~min}, 90 \%(\mathrm{~A})$; and $10 \mathrm{~min}, 90 \%$ (A). Detection wavelength was set at $254 \mathrm{~nm}$ and the flow rate was $1.0 \mathrm{~mL} / \mathrm{min}$. The column temperature was set at $25^{\circ} \mathrm{C}$. All samples were centrifuged at $12,000 \mathrm{rpm}$, at $4{ }^{\circ} \mathrm{C}$ for $10 \mathrm{~min}$. The supernatants were filtered through a $0.22 \mu \mathrm{m}$ membrane filter before injected into the UFLC instrument for analysis.

Decolorization and COD removal efficiencies (\%) were calculated as follows [5]:

Removal efficiency $(\%)=\left(1-C_{t} / C_{0}\right) \times 100 \%$

where $C_{0}$ is the initial concentration of AO7 or COD and $\mathrm{Ct}$ is the concentration at the reaction time t. Current was calculated based on the external resistance using Ohm's law. 

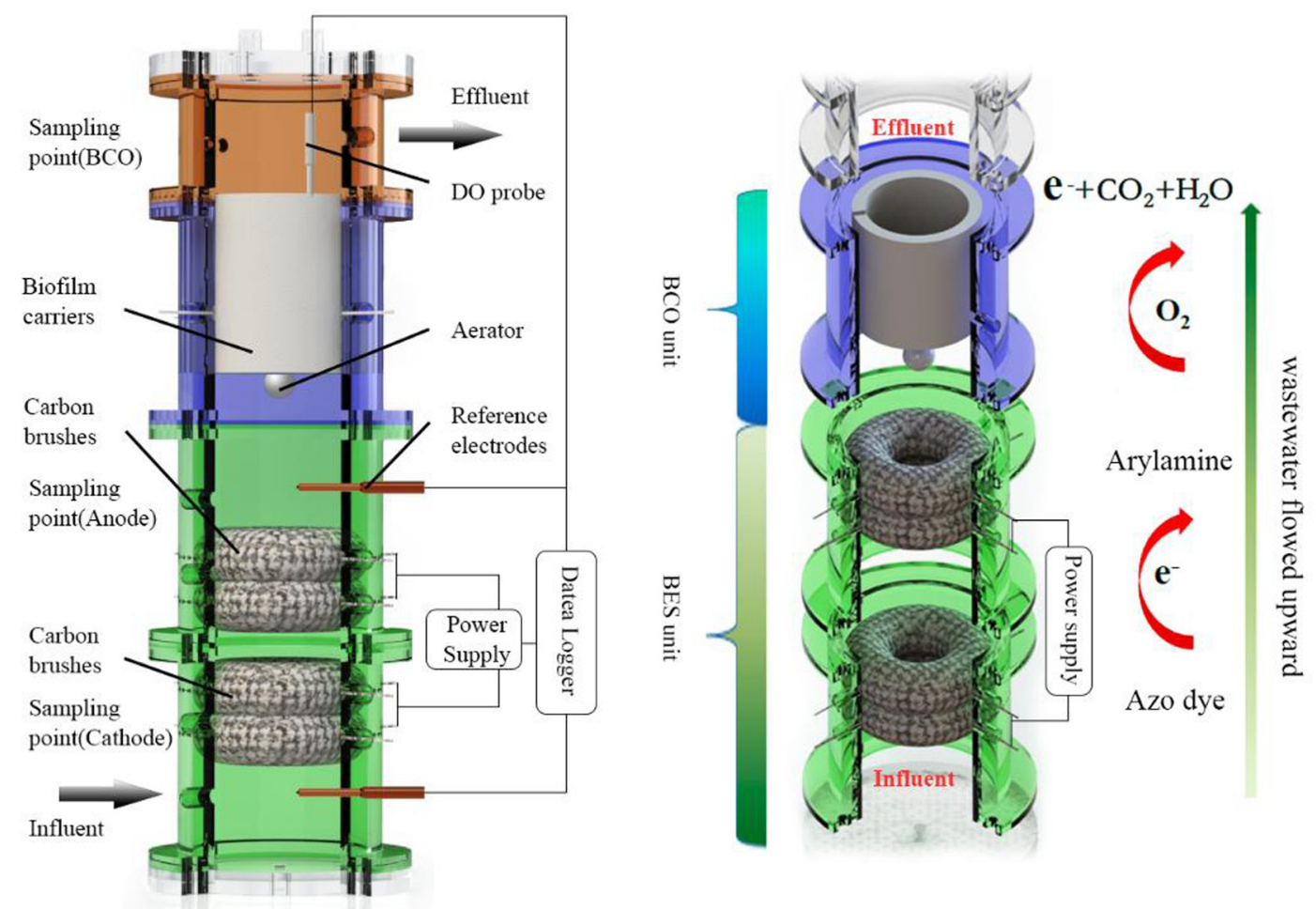

Fig. 1. Schematic diagram of BES-BCO reactor.

\section{Results and discussion}

\subsection{Inoculation and start-up}

The start-up period of BES-BCO system lasted for 40 days and can be divided into three stages as shown in Fig. 2 . In the first stage, the BES and BCO units were operated in batch mode separately. For the BES unit, a reflux pump was used to pump the solution at $4 \mathrm{~L} / \mathrm{min}$ from the anode back to the cathode. Acceleration of the inner circulation was found to have reduced the startup time and maintained the bio-electrodes in a high microorganism concentration setting. For the BCO unit, the biofilm carriers were inoculated with the aerobic sludge of $4-5 \mathrm{mg} / \mathrm{L} \mathrm{DO}$ concentration. After inoculation for 22 days, the current in the BES unit increased from 0 to $16.57 \mathrm{~mA}$ (Fig. 2). The anode and cathode potentials decreased to $-489 \mathrm{mV}$ and $-1082 \mathrm{mV}$, respectively and reached a relatively stable status. The COD concentration in BCO unit reached $53 \pm 11 \mathrm{mg} / \mathrm{L}$ after feeding 24 days, achieving a COD removal efficiency of $94.7 \%$. This indicated that BCO unit was started up successfully.

At second stage, the reflux in BES unit was canceled and changed to continuous operation. The current decreased to $9.47 \mathrm{~mA}$ rapidly due to the decrease in inner flow rate of fluid. After 4 days, the current achieved stability at $8.8 \pm 0.25 \mathrm{~mA}$, while DE was $72.44 \%$. Therefore, it can be concluded that the BES unit was started up successfully. At third stage, the BES and the BCO units were integrated to establish the BES-BCO system. The anode potentials increased from $-458 \mathrm{mV}$ to $-184 \mathrm{mV}$ rapidly at day 27 and 28 since the bioelectrochemical activity is affected by the high DO concentration around the anode. From day 29 to 40, the anode potentials recovered to $-440 \mathrm{mV}$, while the current increased to a stable $12.02 \mathrm{~mA}$, which is higher than the current at stage II. It can be concluded that the aeration process in BCO unit of the BES-BCO system provides oxygen to the microbes on biofilm carriers in addition to leading the inner liquid flowing in the system.

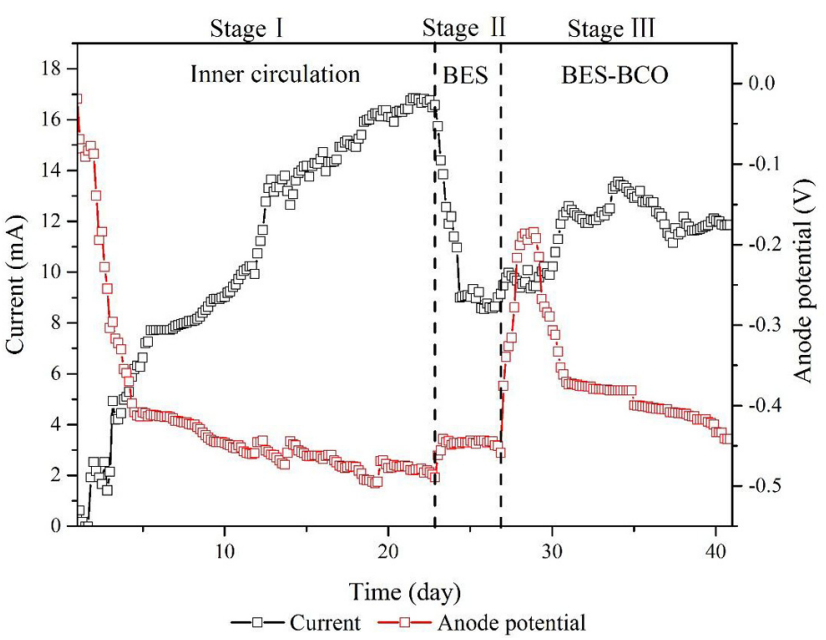

Fig. 2. Current profiles of BES and BES-BCO bioreactor during the start-up.

Micrographs taken from the bio-electrodes and biofilm carriers show that a biofilm developed on both electrodes and biofilm carriers (Fig. 3).

\subsection{Degradation of AO7 and decolorized products}

\subsubsection{Decolorization of $A O 7$}

After start-up, the BES-BCO system was operated in continuous mode at different AO7 concentrations (50, and $100 \mathrm{mg} / \mathrm{L}$ ), a hydraulic retention time (HRT) of $24 \mathrm{~h}$ and voltage of $0.7 \mathrm{~V}$. As shown in Fig. 4, the AO7 concentration gradually reduced from cathode, anode to BCO. When the initial AO7 concentration was $50 \mathrm{mg} / \mathrm{L}$, the decolorization efficiency at cathode, anode and BCO regions was $60.6 \pm 5.1 \%, 83.1 \pm 3.8 \%$, and $97 \pm 1.5 \%$, respectively. 


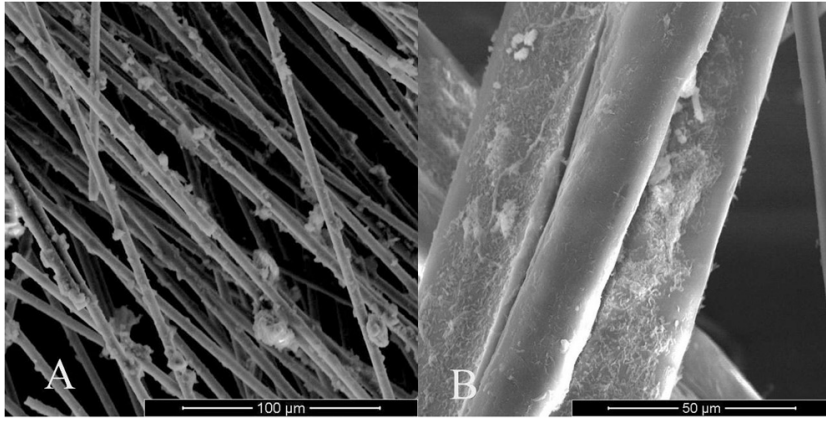

Fig. 3. SEM images of (A) bio-electrode, (B) biofilm carriers with biofilm developed.

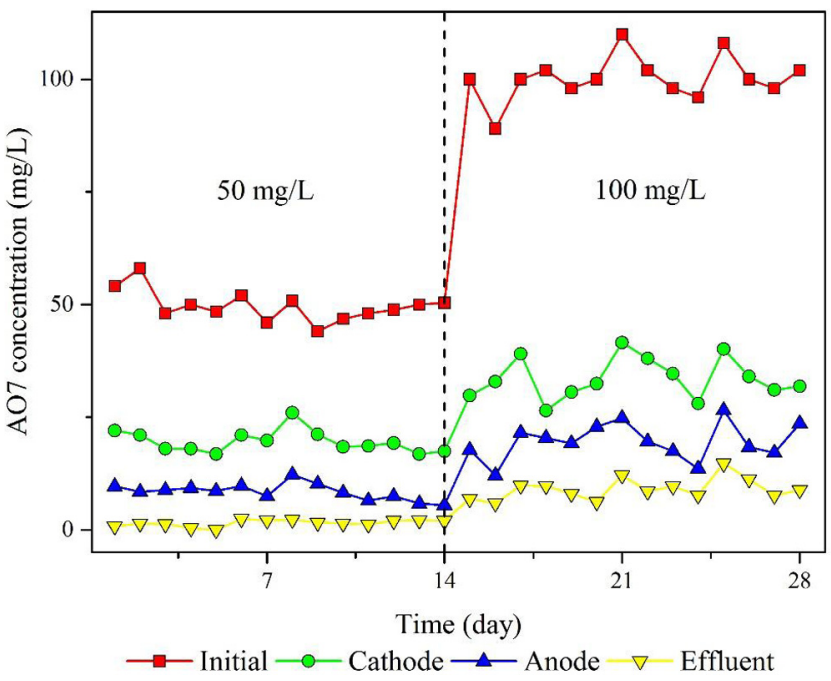

Fig. 4. AO7 concentration monitoring at sampling points in BES-BCO.

The decolorization efficiency was $83.1 \pm 3.8 \%$ after the BES unit suggesting that the BES unit played an important role in AO7 decolorization in the BES-BCO system. The azo bond of AO7 could be broken in anaerobic condition [9], while it is hard in aerobic conditions [15]. In the BES-BCO system, additional AO7 decolorization can occur in the BCO unit due to the biodecolorization by some anaerobic bacteria inside the biofilm carriers.

The AO7 concentration in effluent increased from $1.49 \pm 0.7 \mathrm{mg} /$ $\mathrm{L}$ to $9 \pm 2.4 \mathrm{mg} / \mathrm{L}$ after the influent AO7 concentration increased to $100 \mathrm{mg} / \mathrm{L}$. The decolorization efficiency at the cathode increased to $66.5 \pm 3.9 \%$, while the decolorization efficiency at anode and BCO decreased slightly to $80.4 \pm 3.3 \%$ and $91 \pm 2.0 \%$, respectively. It can be because the toxicity of $\mathrm{AO} 7$ and decolorization byproducts can inhibit the anaerobic degradation of $\mathrm{AO} 7$ at anode and $\mathrm{BCO}$ biofilm carriers.

The current and power densities under different applied voltage at different $\mathrm{AO} 7$ concentrations in BES-BCO were studied. With the increase in applied voltage, current density increased linearly (Fig. 5). The maximum current density was $6.52 \mathrm{~A} / \mathrm{m}^{3}$, while the maximum power density was $4.57 \mathrm{~W} / \mathrm{m}^{3}$ for $100 \mathrm{mg} / \mathrm{L}$ AO7 influent concentration under an applied voltage of $0.7 \mathrm{~V}$. The linear fit for current density can be used to analyze the performance of the system. The current density increased under $12.09 \mathrm{~A} / \mathrm{m}^{3}$ per volt at $100 \mathrm{mg} / \mathrm{L} A O 7$ influent. Using $R=E / I$, the resistance was calculated as $50.10 \Omega$. As the influent AO7 concentration decreased from $100 \mathrm{mg} / \mathrm{L}$ to $50 \mathrm{mg} / \mathrm{L}$, the current density only slightly reduced. When the applied voltage was $0.7 \mathrm{~V}$ and the concentration was $50 \mathrm{mg} / \mathrm{L}$, the maximum current and power densities were $6.33 \mathrm{~A} / \mathrm{m}^{3}$ and $4.43 \mathrm{~W} / \mathrm{m}^{3}$ respectively.

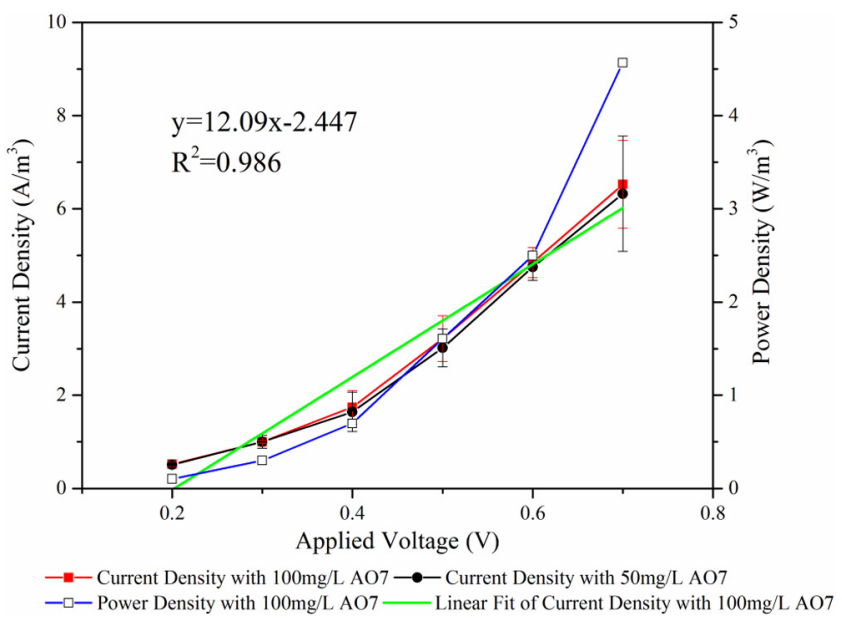

Fig. 5. Polarization curves at different AO7 concentrations in BES-BCO.

\subsubsection{Degradation of decolorized products}

In the BES-BCO system, the azo bond of AO7 was broken in anaerobic condition at the cathode of BES, which was used as the electron donor for AO7 decolorization, to form colorless breakdown byproducts, namely sulfanilic acid (SA) and 1-amino-2naphthol [9]. Ref. [16] reported that the 1-amino-2-naphthol easily undergoes autoxidation reaction even in the presence of only lower amount of oxygen. However, SA, which is the colorless breakdown products, was toxic [17] and difficult to be biodegraded by anaerobic bacteria at anaerobic conditions. Thus, it is necessary to investigate further treatment process of these toxic decolorized byproducts.

As the AO7 containing wastewater flowed upward, the decolorized byproducts can be degraded or mineralized at BCO unit. Fig. 6(A) shows the UV absorbance spectra for influent and effluent from the BES-BCO. The maximum absorption peak for azo bond at $484 \mathrm{~nm}$ almost disappeared from BES-BCO effluent spectrum. The AO7 and SA degradation at different regions of BES-BCO under a HRT of $24 \mathrm{~h}$, a voltage of $0.7 \mathrm{~V}$ is given in Fig. 6(B). The AO7 concentration decreased gradually along BES-BCO system. The concentration of SA increased to the maximum of $29.06 \pm 2.7 \mathrm{mg} / \mathrm{L}$ at cathode and then decreased gradually to $20.08 \pm 2.1 \mathrm{mg} / \mathrm{L}$ from cathode to anode. Finally, the concentration of SA of effluent reached $5.54 \pm 1.6 \mathrm{mg} / \mathrm{L}$. The results indicated that the SA mainly formed at cathode due to azo dye decolorization, and that the SA could be oxidized at anode and BCO unit. The decolorized products do not degrade well under anaerobic condition [18]. However, trace dissolved oxygen was delivered to anode area due to the integrated aerobic BCO unit. The aromatic amines produced due to azo dye reduction is highly reactive in the presence of oxygen [19]. Thus, bacteria on anode could use SA under trace oxygen condition. In the $\mathrm{BCO}$ unit, the SA concentration decreased indicating that the SA could be degraded efficiently at BCO unit.

\subsection{COD removal}

The COD removal performance was investigated for different AO7 initial concentrations. As shown in Fig. 7(A), when the initial influent COD concentration was $1000 \mathrm{mg} / \mathrm{L}$ without the presence of AO7 in the BES-BCO system, the COD concentrations at cathode, anode and effluent were $585.7 \pm 53.5 \mathrm{mg} / \mathrm{L}, 467.9 \pm 63.4 \mathrm{mg} / \mathrm{L}$, and $98.6 \pm 35.1 \mathrm{mg} / \mathrm{L}$, respectively. This indicates that both BES and BCO units played a significant role in the removal of COD in the BES-BCO system. As the influent AO7 concentration increased, the COD removal efficiency exhibited a descending tendency at 


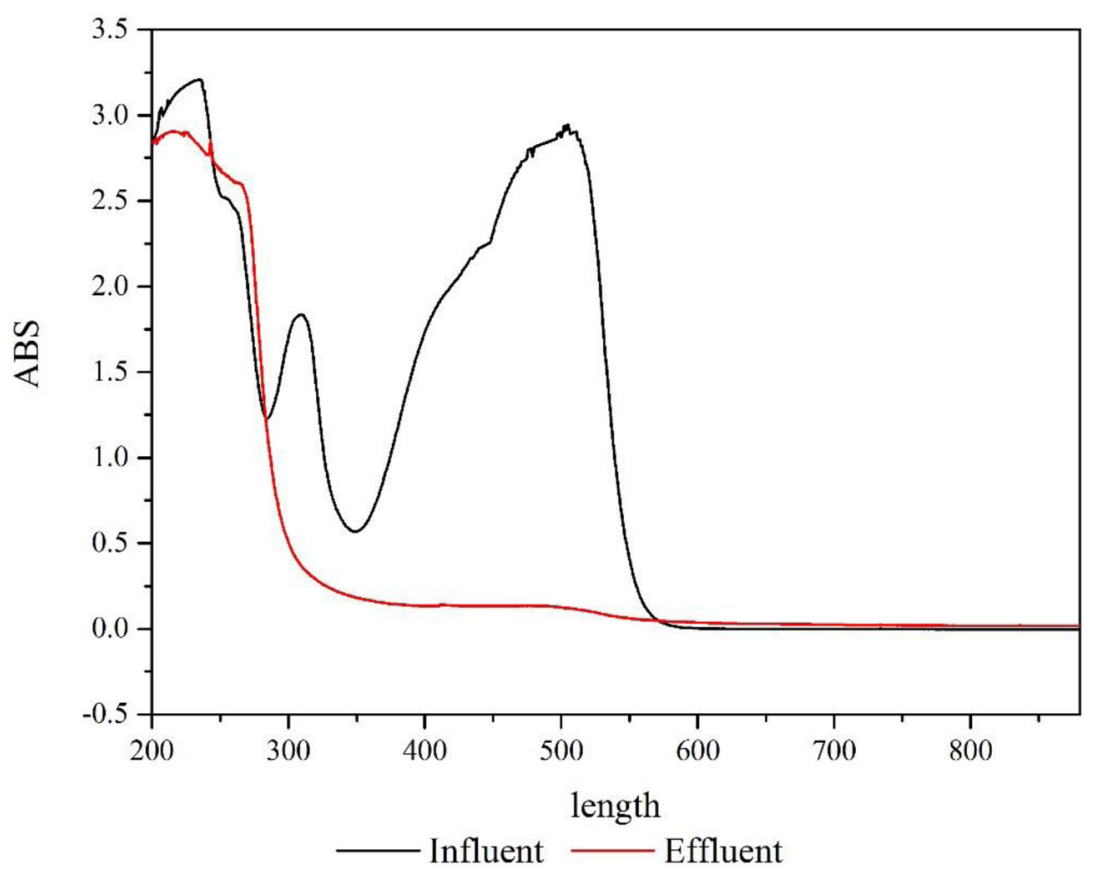

\section{(A)}

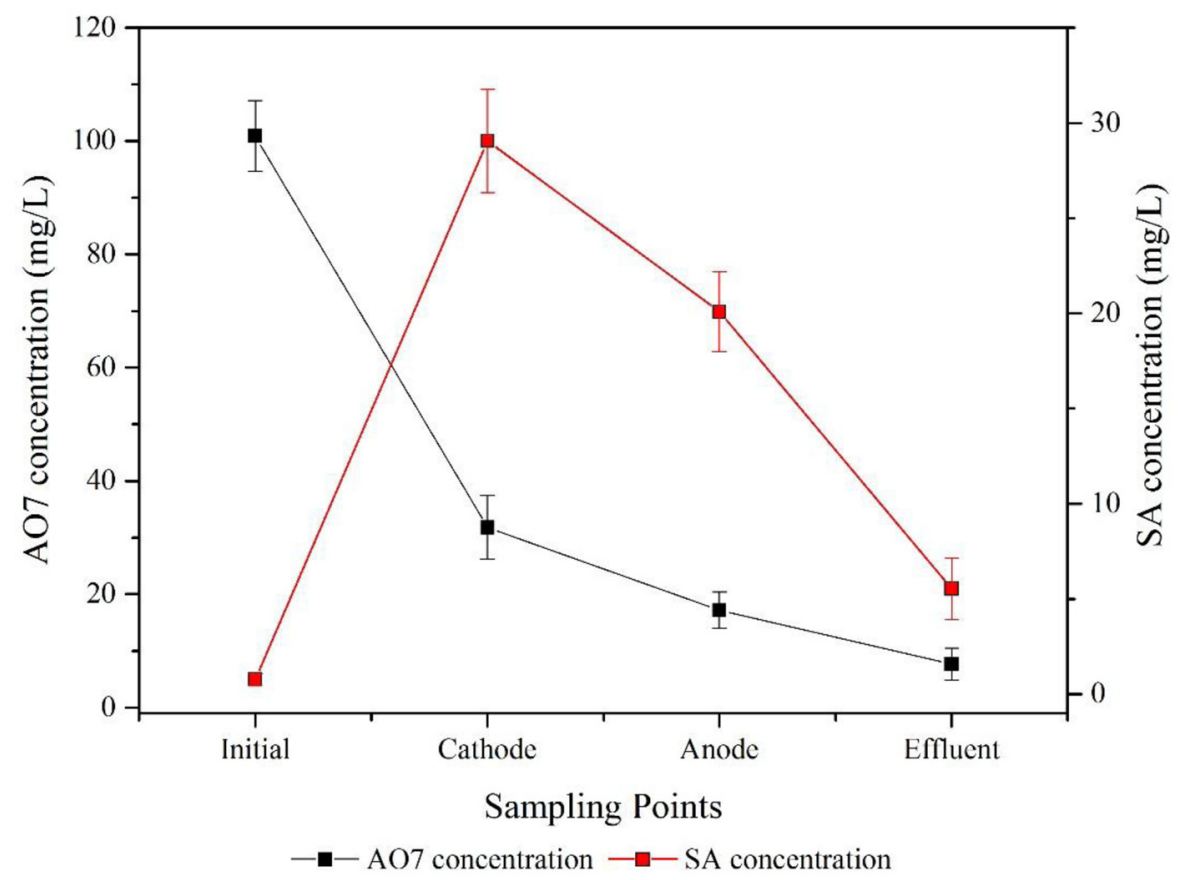

(B)

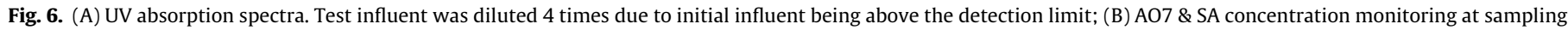
points in BES-BCO.

cathode and anode. The COD concentration along cathode and anode, and in effluent increased to $764.0 \pm 88.0 \mathrm{mg} / \mathrm{L}$, $614.5 \pm 67.8 \mathrm{mg} / \mathrm{L}$, and $166.2 \pm 38.2 \mathrm{mg} / \mathrm{L}$, respectively, when the influent AO7 concentration was $100 \mathrm{mg} / \mathrm{L}$. This can be attributed to the toxicity due to high AO7 concentration and decolorized products, which can inhibit growth of bacteria on BES electrochemical active biofilms and BCO biofilms [20,21].
Fig. 7(B) shows the COD concentration and removal efficiency at different regions of BES-BCO for a HRT of about $24 \mathrm{~h}$, and the influent AO7 concentration of $100 \mathrm{mg} / \mathrm{L}$. The COD removal efficiency was $22.36 \pm 9.18 \%, 37.62 \pm 6.60 \%, 83.16 \pm 3.67 \%$ at cathode, anode and in effluent, respectively. The BCO region experienced higher removal of $C O D$, suggesting that the $B C O$ unit played the primary role in the removal of $\mathrm{COD}$ in the $\mathrm{BES}-\mathrm{BCO}$ reactor. 


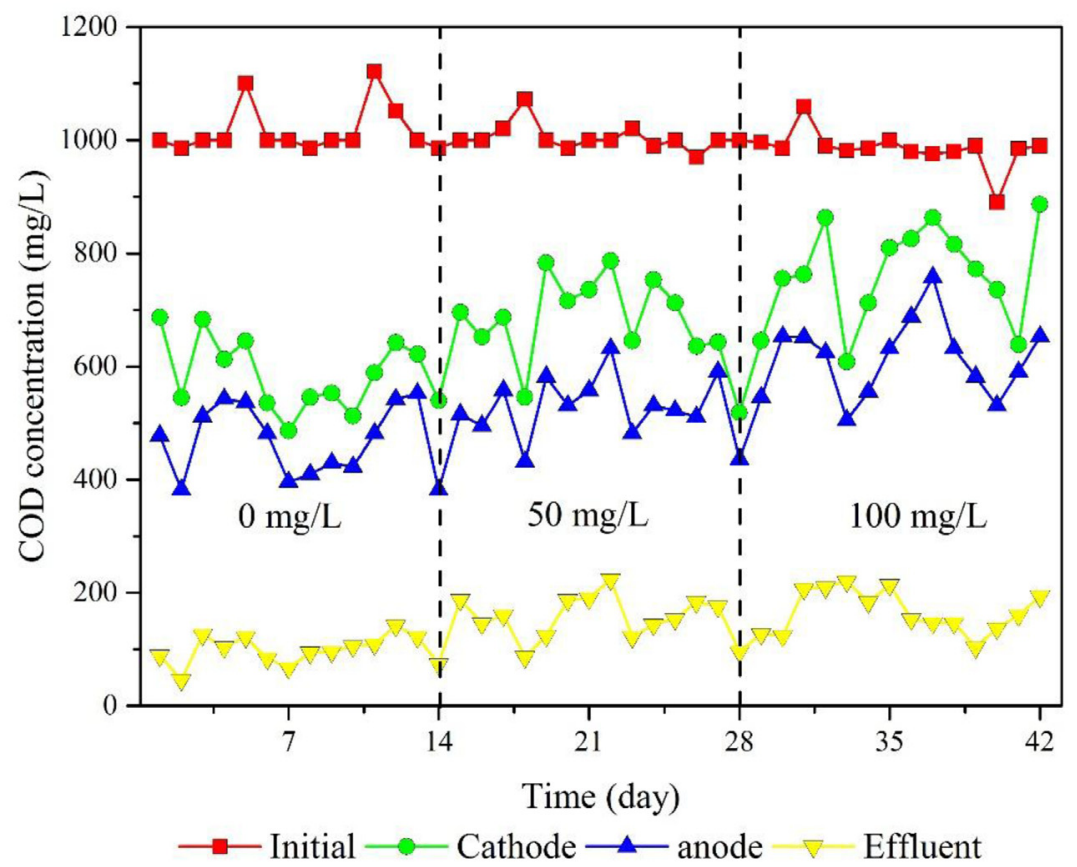

(A)

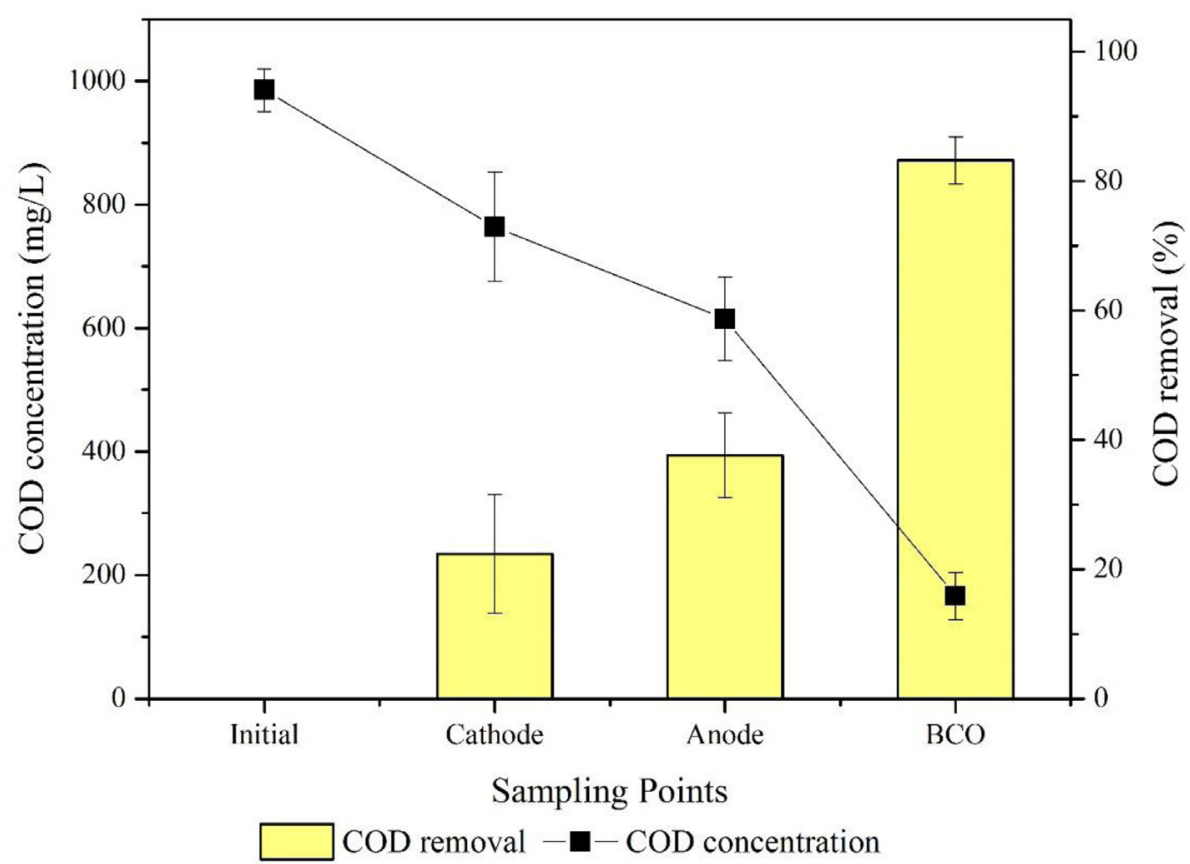

(B)

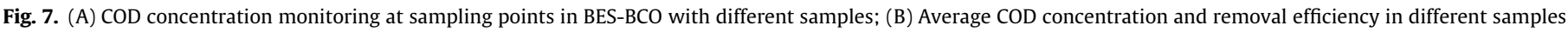
within 24 h HRT.

\subsection{Effect of DO concentration on the BES-BCO system}

The anode in the conventional BES system is operated anaerobically to prevent the loss of microbial reduction power due to oxygen. Adequate DO is important for the microbial growth on biofilm carries in the BCO unit. Thus, the concentration of DO is a critical factor in the BES-BCO system. In this study, the effect of DO concentration on AO7\&COD removal efficiency was investigated. As shown in Fig. 8, the DO concentration at anode decreased to nearly $0 \mathrm{mg} / \mathrm{L}$ due to oxygen consumption through the aerobic respiration process of microbes on the BCO bio-carries, when the DO concentration was controlled at $0.5-1.5 \mathrm{mg} / \mathrm{L}$ in the BCO unit. After DO concentration increased to $2.6-3 \mathrm{mg} / \mathrm{L}$ at $\mathrm{BCO}$, the COD removal efficiency increased from $58.17 \pm 4.09 \%$ to $82.37 \pm 3.74 \%$, while the AO7 removal efficiency increased slightly from $86.91 \pm 2.69 \%$ to $92.93 \pm 2.28 \%$. Further, increased DO can lead to increased bio- 


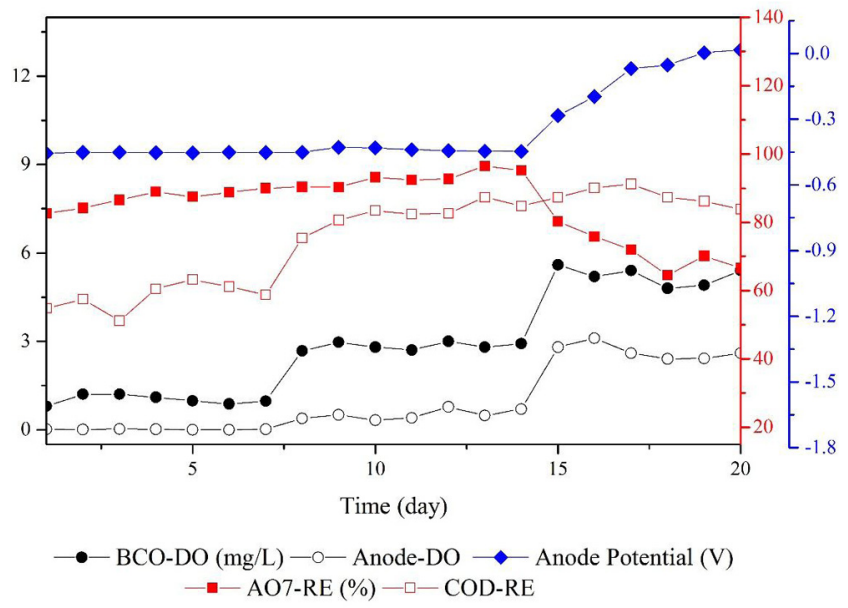

Fig. 8. DO concentration at BCO and anode and AO7 \& COD removal efficiency of effluent.

mass formation at the BCO biofilm carries. For the BCO, the aeration at the bottom can generate an upward flow and then the increased aeration airflow can lead to the flow of an inner liquid in system to enhance the aerobic biomass mass transfer. Meanwhile, the DO concentration in anode was controlled in the range of $0.32-0.77 \mathrm{mg} / \mathrm{L}$, and the anode potential was relatively stable at $-446 \mathrm{mV}$ indicating that trace oxygen was not affected notably with microbial electron generation at anode.

However, excessive DO at BCO (4.8-5.6 mg/L) caused an increase in DO concentration at anode to $2.4-3.1 \mathrm{mg} / \mathrm{L}$, resulting in an increase in the anode potential to $162.5 \mathrm{mV}$. This indicates that high DO concentration significantly inhibited the activity of electrochemically active bacteria on anode. The AO7 removal efficiency decreased to $71.5 \pm 5.8 \%$, though the COD removal efficiency increased to $87.6 \pm 2.7 \%$. The AO7 removal efficiency was significant reduced in the BES-BCO system since reducing equivalents (electrons) were partially dissipated by the supplied oxygen [22]. Because of oxygen, BES system could not perform electrochemical decolorized reduction. Without the decolorization of BES cathode, the BES-BCO system was still able to degrade azo dyes under high DO concentration, which may be due to the anaerobic biofilms. DO, at high concentration, was beneficial to the growth of biofilm on BCO carrier leading to an increase in the biofilm thickness, which can be useful in the anaerobic layer formation. It is generally known that the anaerobic microbes can degrade the azo dyes using azo reductases [23]. Due to the sufficient oxygen supply, increased biomass at biofilm carriers led to efficient removal of COD, especially the glucose in azo dye wastewater. However, the requirement for a high aeration intensity increased the energy consumption and decreased the azo dye removal efficiency, although the COD removal was more efficient than the previous case.

\subsection{Effect of ionic strength and temperature on the BES-BCO system}

The phosphate buffer solution (PBS) can enhance the conductivity of electrode and maintain neutral $\mathrm{pH}$ to ensure the normal growth of electrochemically active bacteria. Increasing the ionic strength (IS) could increase solution conductivity and decrease internal resistance of BES system. In this study, solution conductivity was increased by increasing PBS concentration $(0,50$, and $100 \mathrm{mM}$ ) to show the effect of IS on BES-BCO performance (Table 1). As IS increased, the anode potential decreased slightly, while the cathode potential increased. Similar result was reported by Liu et al. in the MFC system. The anode working potential decreased and the cathode working potential increased with the increase in the ionic strength, producing a greater overall circuit voltage [24]. The increase in IS changed the potentials of both electrodes, resulting in a decrease in internal resistance. With the increase in solution ionic strength, the current density enhanced and reached the maximum of $8.57 \mathrm{~A} / \mathrm{m}^{3}$ when $100 \mathrm{mM}$ PBS was added. The current density was 31\% larger than that obtained with $50 \mathrm{mM}$ PBS and 211\% larger than that obtained without PBS $(0 \mathrm{mM})$. However, increasing IS had less influence on the removal of azo dye and COD in BES-BCO system.

It is well known that temperature has important influence on bacterial activities. Many studies maintained $30-37^{\circ} \mathrm{C}$ in the BES system. However, in wastewater treatment, the reactor is always operated at lower temperature to reduce the operational costs. In this study, the performance of BES-BCO under different temperature $\left(15^{\circ} \mathrm{C}, 25^{\circ} \mathrm{C}\right.$, and $\left.35^{\circ} \mathrm{C}\right)$ was investigated. The results show that the potential of both electrodes and current density did not change significantly under different temperature. However, removal effect, especially the COD removal effect, was enhanced due to increasing temperature in the BES-BCO system. The COD removal efficiency increased from $76.6 \%$ to $88.4 \%$ with the increase in temperature from 15 to $35^{\circ} \mathrm{C}$. The increase of biological activity in microbes and the increase in biomass in electrodes and biofilm carriers could have led to enhanced removal efficiency at higher temperature.

\subsection{Possible mechanism for the removal of azo dye removed and byproducts in BES-BCO reactor}

Firstly, the azo bond in $\mathrm{AO} 7$ was broken at the cathode by reduction to form colorless aniline compounds. Yang et al. observed a negative effect of DO on the azo dye in the cathode chamber decolorization [25]. The DO concentration at the biocathode of BES-BCO was below $0.05 \mathrm{mg} / \mathrm{L}$, which could have reduced the electrons loss through oxygen as the competitive electron. The decolorization efficiency was more than $60 \%$ after the treatment at the bio-cathode, suggesting that the AO7 decolorization in the BES-BCO system mainly depended on the bio-cathode reduction. The breakdown products, namely sulfanilic acid and 1amino-2-naphthol, are difficult to degrade at anaerobic conditions. The peak SA concentration was achieved at cathode in BES-BCO system.

Fig. $6 \mathrm{~B}$ shows that the $\mathrm{AO} 7$ concentration was further decreased at anode, indicating that azo dyes were further degraded by anaerobic microbes at bio-anode. The SA are difficult to biodegrade due to the hydrophilic nature of the sulfonate group, which obstructs membrane transport [19]. However, in this study, the SA concentration decreased at anode. It may be due to the effect of trace oxygen in anode. Cheng et al. reported that electricity generation from aniline, which a typical recalcitrant organic matter under anaerobic condition, was remarkably facilitated by employing oxygen into bioanode of MFCs. The amine production could be used as electron donor at the O-bioanode [11]. In addition, trace oxygen can stimulate bacterial growth, and increase the biofilm thickness. The biofilm provided a more anoxic condition inside for electrochemically active bacteria to favor the terminal electron transfer to anode than oxygen transfer.

At BCO part, the concentration of SA decreased, indicating that the breakdown products of azo dye could be mineralized aerobically. The amines, which are the azo dye breakdown products, were mineralized by different members of the aerobic bacterial culture [26]. Meanwhile, about $45 \%$ of the COD was removed by BCO. It is possible to improve the biodegradability of azo dye after treatment at BES. Similar result was reported by Ong et al., in which the anaerobic process improved biodegradability of azo 
Table 1

Effect of PBS concentration and temperature on BES-BCO performance.

\begin{tabular}{|c|c|c|c|c|c|c|}
\hline PBS concentration & Temperature $\left({ }^{\circ} \mathrm{C}\right)$ & Anode potential (V) & Cathode potential (V) & Current density $\left(\mathrm{A} / \mathrm{m}^{3}\right)$ & AO7 removal (\%) & COD removal (\%) \\
\hline $0 \mathrm{mM}$ & 25 & -0.408 & -1.093 & 2.75 & 88.5 & 81.2 \\
\hline $50 \mathrm{mM}$ & 25 & -0.425 & -1.011 & 6.53 & 91.3 & 83.1 \\
\hline $100 \mathrm{mM}$ & 25 & -0.448 & -0.831 & 8.57 & 94.7 & 79.2 \\
\hline $50 \mathrm{mM}$ & 15 & -0.424 & -1.018 & 5.71 & 86.2 & 76.6 \\
\hline $50 \mathrm{mM}$ & 35 & -0.412 & -1.031 & 6.54 & 92.6 & 88.4 \\
\hline
\end{tabular}

dye for further aerobic treatment in a two-stage sequential UASBSBR system [27].

\section{Conclusions}

The study found that the BES-BCO, which is an integrated system of advanced treatment methods, has the capability for efficient COD reduction, and AO7 decolorization. The decolorized products were further degraded by bio-contact oxidation. Furthermore, electrochemically active bacteria activity on anode was inhibited at high DO concentration and the performance of AO7 decolorization reduced indicating that the oxygen and $\mathrm{AO} 7$ competed as electron acceptor. Therefore, it is important to control the DO concentration in the BES-BCO system. The BES-BCO is a novel treatment system for the removal of azo dye or other pollutants in wastewater in engineering application.

\section{Acknowledgement}

This research was supported by the China Postdoctoral Science Foundation (2015M570255), the Fundamental Research Funds for the Central Universities of China (N140303002), the Science Technology Foundation of Liaoning Educational Committee (L20150178), and the National Natural Science Foundation of China (51608099).

\section{References}

[1] K. Selvam, K. Swaminathan, K.S. Chae, Microbial decolorization of azo dyes and dye industry effluent by Fomes lividus, World J. Microbiol. Biotechnol. 19 (2003) 591-593.

[2] F.P. Van der Zee, G. Lettinga, J.A. Field, Azo dye decolourisation by anaerobic granular sludge, Chemosphere 44 (2001) 1169-1176.

[3] C. O'neill, A. Lopez, S. Esteves, F. Hawkes, D. Hawkes, S. Wilcox, Azo-dye degradation in an anaerobic-aerobic treatment system operating on simulated textile effluent, Appl. Microbiol. Biotechnol. 53 (2000) 249-254.

[4] D. Cui, Y.Q. Guo, H.S. Lee, H.Y. Cheng, B. Liang, F.Y. Kong, Y.Z. Wang, L.P. Huang, M.Y. Xu, A.J. Wang, Efficient azo dye removal in bioelectrochemical system and post-aerobic bioreactor: optimization and characterization, Chem. Eng. J. 243 (2014) 355-363.

[5] Y.Z. Wang, A.J. Wang, W.Z. Liu, D.Y. Kong, W.B. Tan, C. Liu, Accelerated azo dye removal by biocathode formation in single-chamber biocatalyzed electrolysis systems, Bioresour. Technol. 146 (2013) 740-743.

[6] F. Kong, A. Wang, H.Y. Ren, Improved azo dye decolorization in an advanced integrated system of bioelectrochemical module with surrounding electrode deployment and anaerobic sludge reactor, Bioresour. Technol. 175 (2015) 624628.

[7] D. Cui, Y.Q. Guo, H.Y. Cheng, B. Liang, F.Y. Kong, H.S. Lee, A.J. Wang, Azo dye removal in a membrane-free up-flow biocatalyzed electrolysis reactor coupled with an aerobic bio-contact oxidation reactor, J. Hazard. Mater. 239-240 (2012) 257-264.
[8] W.E. Thung, S.A. Ong, L.N. Ho, Y.S. Wong, F. Ridwan, Y.L. Oon, Y.S. Oon, H.K. Lehl, A highly efficient single chambered up-flow membrane-less microbial fuel cell for treatment of azo dye Acid Orange 7-containing wastewater, Bioresour. Technol. 197 (2015) 284-288.

[9] Y. Mu, K. Rabaey, R.A. Rozendal, Z.G. Yuan, J. Keller, Decolorization of azo dyes in bioelectrochemical systems, Environ. Sci. Technol. 43 (2009) 5137-5143.

[10] H. Ødegaard, A road-map for energy-neutral wastewater treatment plants of the future based on compact technologies (including MBBR), Front. Environ. Sci. Eng. 10 (2016) 1-17.

[11] H.Y. Cheng, B. Liang, Y. Mu, M.H. Cui, K. Li, W.M. Wu, A.J. Wang, Stimulation of oxygen to bioanode for energy recovery from recalcitrant organic matter aniline in microbial fuel cells (MFCs), Water Res. 81 (2015) 72-83.

[12] E. Wolin, M.J. Wolin, R. Wolfe, Formation of methane by bacterial extracts, J. Biol. Chem. 238 (1963) 2882-2886.

[13] B. Donlon, E. Razo Flores, M. Luijten, H. Swarts, G. Lettinga, J. Field, Detoxification and partial mineralization of the azo dye mordant orange 1 in a continuous upflow anaerobic sludge-blanket reactor, Appl. Microbiol. Biotechnol, 47 (1997) 83-90.

[14] A.A. Wef, Standard Methods for the Examination of Water and Wastewater, Washington DC, 1998.

[15] E. Fernando, T. Keshavarz, G. Kyazze, Complete degradation of the azo dye Acid Orange 7 and bioelectricity generation in an integrated microbial fuel cell, aerobic two-stage bioreactor system in continuous flow mode at ambient temperature, Bioresour. Technol. 156 (2014) 155-162.

[16] M. Kudlich, M.J. Hetheridge, H.J. Knackmuss, A. Stolz, Autoxidation reactions of different aromatic o-aminohydroxynaphthalenes that are formed during the anaerobic reduction of sulfonated azo dyes, Environ. Sci. Technol. 33 (1999) 896-901.

[17] F.P. Van Der Zee, I.A. Bisschops, G. Lettinga, J.A. Field, Activated carbon as an electron acceptor and redox mediator during the anaerobic biotransformation of azo dyes, Environ. Sci. Technol. 37 (2003) 402-408.

[18] N. Kishimoto, N. Matsuda, Bromate ion removal by electrochemical reduction using an activated carbon felt electrode, Environ. Sci. Technol. 43 (2009) 20542059.

[19] F.P. van der Zee, S. Villaverde, Combined anaerobic-aerobic treatment of azo dyes-a short review of bioreactor studies, Water Res. 39 (2005) 1425-1440.

[20] S. Asad, M.A. Amoozegar, A.A. Pourbabaee, M.N. Sarbolouki, S.M.M. Dastgheib, Decolorization of textile azo dyes by newly isolated halophilic and halotolerant bacteria, Bioresour. Technol. 98 (2007) 2082-2088.

[21] K.C. Chen, J.Y. Wu, D.J. Liou, S.C.J. Hwang, Decolorization of the textile dyes by newly isolated bacterial strains, J. Biotechnol. 101 (2003) 57-68.

[22] M. Rosenbaum, M.A. Cotta, L.T. Angenent, Aerated Shewanella oneidensis in continuously fed bioelectrochemical systems for power and hydrogen production, Biotechnol. Bioeng. 105 (2010) 880-888.

[23] C.I. Pearce, J.R. Lloyd, J.T. Guthrie, The removal of colour from textile wastewater using whole bacterial cells: a review, Dyes Pigm. 58 (2003) 179-196.

[24] H. Liu, S. Cheng, B.E. Logan, Power generation in fed-batch microbial fuel cells as a function of ionic strength, temperature, and reactor configuration, Environ. Sci. Technol. 39 (2005) 5488-5493.

[25] H.Y. Yang, C.S. He, L. Li, J. Zhang, J.Y. Shen, Y. Mu, H.Q. Yu, Process and kinetics of azo dye decolourization in bioelectrochemical systems: effect of several key factors, Sci. Rep. 6 (2016).

[26] W. Haug, A. Schmidt, B. Nörtemann, D. Hempel, A. Stolz, H. Knackmuss, Mineralization of the sulfonated azo dye Mordant Yellow 3 by a 6aminonaphthalene-2-sulfonate-degrading bacterial consortium, Appl. Environ. Microbiol. 57 (1991) 3144-3149.

[27] S.A. Ong, E. Toorisaka, M. Hirata, T. Hano, Decolorization of azo dye (Orange II) in a sequential UASB-SBR system, Sep. Purif. Technol. 42 (2005) 297-302. 